\section{Integral role of Noxa in p53-mediated apoptotic response}

\author{
Tsukasa Shibue, ${ }^{1}$ Kiyoshi Takeda, ${ }^{3}$ Eri Oda, ${ }^{1,4}$ \\ Hiroshi Tanaka, ${ }^{1}$ Hideki Murasawa, ${ }^{1}$ \\ Akinori Takaoka, ${ }^{1}$ Yasuyuki Morishita, ${ }^{2}$ \\ Shizuo Akira, ${ }^{3}$ Tadatsugu Taniguchi, ${ }^{1,5}$ and \\ Nobuyuki Tanaka ${ }^{1,4}$
}

${ }^{1}$ Department of Immunology and ${ }^{2}$ Department of Pathology, Graduate School of Medicine and Faculty of Medicine, University of Tokyo, Bunkyo-ku, Tokyo 113-0033, Japan, ${ }^{3}$ Department of Host Defense, Research Institute for Microbial Diseases, Osaka University, Suita-shi, Osaka 565-0871, Japan, and ${ }^{4}$ Department of Molecular Oncology, Institute of Gerontology, Nippon Medical School,

Nakahara-ku, Kawasaki-shi 211-8533, Japan

The tumor suppressor $\mathbf{p} 53$ exerts its versatile function to maintain the genomic integrity of a cell, and the life of cancerous cells with DNA damage is often terminated by induction of apoptosis. We studied the role of Noxa, one of the transcriptional targets of p53 that encodes a proapoptotic protein of the Bcl-2 family, by the gene-targeting approach. Mouse embryonic fibroblasts deficient in Noxa [Noxa ${ }^{-/-}$mouse embryonic fibroblasts (MEFs)] showed notable resistance to oncogene-dependent apoptosis in response to DNA damage, which was further increased by introducing an additional null zygosity for Bax. These MEFs also showed increased sensitivity to oncogene-induced cell transformation in vitro. Furthermore, Noxa is also involved in the oncogene-independent gradual apoptosis induced by severe genotoxic stresses, under which $\mathrm{p} 53$ activates both survival and apoptotic pathways through induction of $p 21^{\text {WAF1/Cip1 }}$ and Noxa, respectively. Noxa ${ }^{-/-}$mice showed resistance to $\mathrm{X}$-ray irradiation-induced gastrointestinal death, accompanied with impaired apoptosis of the epithelial cells of small intestinal crypts, indicating the contribution of Noxa to the p53 response in vivo.

Supplemental material is available at http://www.genesdev.org.

Received April 14,. 2003; revised version accepted July 10, 2003.

Numerous genotoxic stresses interfere with the integrity of the genome; hence, cells maintain various mechanisms to avoid genetic alterations that would otherwise cause cell transformation (Lengauer et al. 1998). Depending on the degree and/or the nature of DNA damage, cells undergo either cell cycle arrest or apoptosis in order

[Keywords: p53; apoptosis; Bcl-2 family; DNA damage; oncogene] ${ }^{5}$ Corresponding author.

E-MAIL tada@m.u-tokyo.ac.jp; FAX 81-3-5841-3450.

Article published online ahead of print. Article and publication date are at http://www.genesdev.org/cgi/doi/10.1101/gad.1103603. to allow DNA repair or altruistic suicide of cells, respectively (Rich et al. 2000; Zhou and Elledge 2000). The tumor suppressor p53 is the most prominent factor for the maintenance of genome integrity; p53 is activated in response to DNA damage and plays a key role in determining the fate of cells (Vousden and Lu 2002), mainly through the transcriptional induction of target genes (Ko and Prives 1996).

Among the p53-mediated cellular responses, the induction of apoptosis is central to tumor suppression (Schmitt et al. 2002). In this context, numerous target genes of p53 have been identified that may be involved in p53-dependent apoptosis (Vousden and Lu 2002). However, little is known about the details of this process, particularly with regard to the interrelationship among these target genes. Bax and Bak, which are "multidomain pro-apoptotic members" of the Bcl-2 family, have been shown to play critical roles in apoptotic response (Wei et al. 2001); they form oligomers in the mitochondrial outer membrane to activate the cascade of apoptotic events. Perhaps central to the p53-dependent apoptosis is the induction of genes encoding another class of this family termed BH3-only members, which contribute to this Bax/Bak function either directly by stimulating the oligomerization or indirectly by interacting with "prosurvival members" such as Bcl-2 and Bcl- $\mathrm{X}_{\mathrm{L}}$, which otherwise suppress the Bax/Bak function (Bouillet and Strasser 2002). The p53 target genes of the BH3-only members include Noxa (Oda et al. 2000) and Puma (Nakano and Vousden 2001; Yu et al. 2001). However, up to what extent and how these genes contribute to the p53-dependent apoptosis are currently unknown.

In the present study, we generated mice deficient in Noxa, and examined the cellular response in the context of DNA-damage-induced apoptosis. Our results demonstrate that Noxa is an integral mediator of the p53-dependent apoptosis, but its contribution depends on cell type and cell state.

\section{Results and Discussion}

\section{Targeted disruption of Noxa gene}

To study the functional role of Noxa in the regulation of p53 responses, null mutation in the Noxa allele was introduced through homologous recombination in embryonic stem (ES) cells (Supplementary Fig. 1A). The homozygous mutant mice (Noxa ${ }^{-1-}$ mice) were generated by using standard procedures (see Materials and Methods). The expected recombination was confirmed by Southern blot analysis (Supplementary Fig. 1B). In embryonic fibroblasts from the mutant mice [Noxa ${ }^{-/}$mouse embryonic fibroblasts (MEFs)], neither the mRNA nor the protein for Noxa was detected after treatment with adriamycin, which induces Noxa expression in wild-type MEFs (Supplementary Fig. 1C,D). Developmental abnormalities were not found in the Noxa ${ }^{-/-}$mice, and they lived without any signs of tumor development for at least 1 year after birth (data not shown).

p53-dependent apoptotic responses in Noxa-deficient and Noxa/Bax doubly deficient cells

MEFs expressing the adenovirus-encoded E1A oncoprotein undergo apoptosis in response to the treatment with 
DNA-damaging agents in a p53-dependent manner (Lowe et al. 1993a), and this response is partially attenuated in MEFs lacking the pro-apoptotic member Bax (McCurrach et al. 1997). By using Noxa ${ }^{-/-}$MEFs, we first investigated the extent to which Noxa contributes to this response. When the MEFs were infected with an E1A-expressing retrovirus, followed by treatment with adriamycin, the cells showed higher resistance than did the similarly treated wild-type MEFs from the same litter (Fig. 1A). The resistance of E1A-expressing Noxa ${ }^{-1}$ MEFs was similarly observed in the case of etoposide treatment or X-ray irradiation (data not shown). These results prompted us to further examine the E1A-dependent apoptotic response of MEFs doubly deficient in Noxa and Bax (Noxa $\left.{ }^{-/-} / \mathrm{Bax}^{-/-} \mathrm{MEFs}\right)$. Interestingly, $\mathrm{Noxa}^{-/-} / \mathrm{Bax}^{-/-}$MEFs were even more resistant than either of the single mutant MEFs in the adriamycin-induced apoptosis (Fig. 1A), indicating that Noxa and Bax

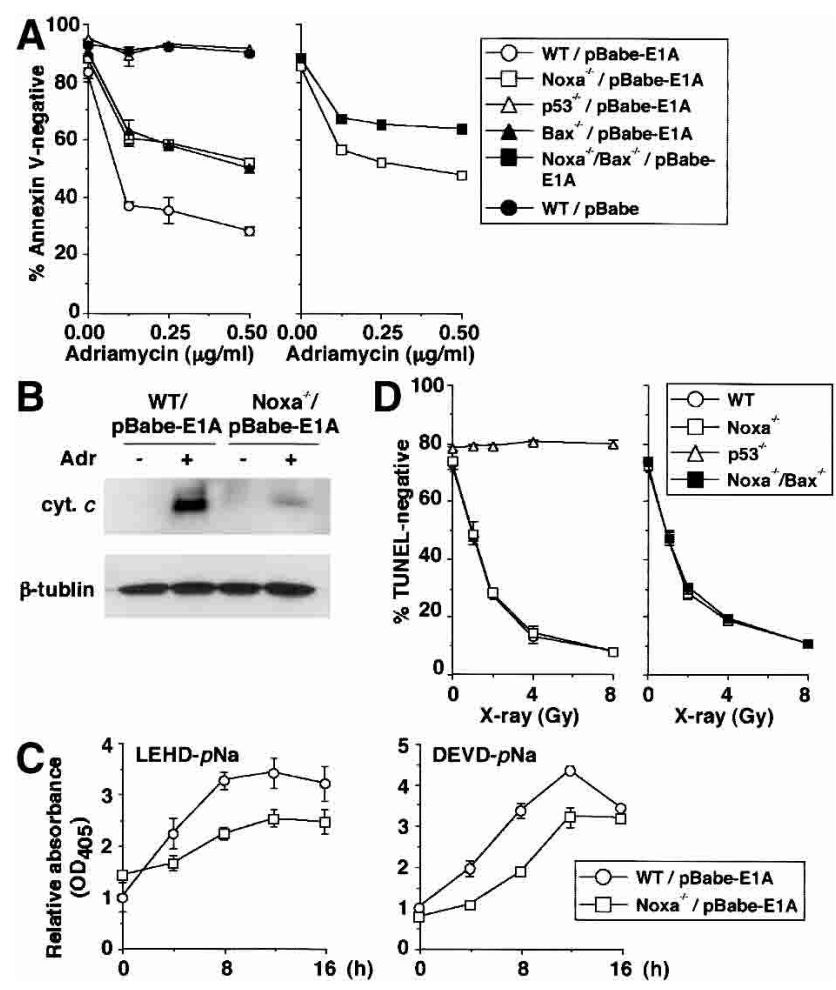

Figure 1. Effect of deficiency in Noxa on p53-mediated apoptotic response. $(A, C, D)$ Values shown are mean \pm S.D. from triplicate samples. (A) DNA damage-induced apoptosis of E1A-expressing MEFs. MEFs were infected with control (pBabe) or E1A-expressing retrovirus (pBabe-E1A), and were treated with adriamycin $(0.25 \mu \mathrm{g} /$ $\mathrm{mL}$ ) for $24 \mathrm{~h}$. Wild-type (WT) and $\mathrm{Noxa}^{-1-}$ MEFs (left), as well as $\mathrm{Noxa}^{-1-}$ and $\mathrm{Noxa}^{-1-} / \mathrm{Bax}^{-1-}$ MEFs (right), were each prepared from the same litter. Results are representative of three independent experiments. $(B)$ Cytochrome $c$ release in E1A-expressing MEFs after adriamycin treatment. E1A-expressing MEFs were treated with adriamycin $(0.25 \mu \mathrm{g} / \mathrm{mL})$ for $12 \mathrm{~h}$. Wild-type (WT) and $\mathrm{Noxa}^{-/} \mathrm{MEFs}$ were prepared from the same litter. cyt. $c$ indicates cytochrome $c$. (C) Caspase activation in E1A-expressing MEFs after adriamycin treatment. E1A-expressing MEFs were treated with adriamycin $(0.25 \mu \mathrm{g} / \mathrm{mL})$ for indicated times. Wild-type (WT) and $\mathrm{Noxa}^{-/-} \mathrm{MEFs}$ were prepared from the same litter. $(D)$ Radiation-induced apoptosis of thymocytes. Thymocytes were X-ray irradiated, and $18 \mathrm{~h}$ later, cell death was quantitated. Wild-type (WT) and Noxa ${ }^{-1-}$ thymocytes (left) as well as Noxa ${ }^{-/-}$and Noxa ${ }^{-1-} / \mathrm{Bax}^{-/-}$thymocytes (right) were each prepared from mice from the same litter. Results are representative of three independent experiments. function through partially parallel mechanisms. On the other hand, Noxa ${ }^{-/-} / \mathrm{Bax}^{-/-}$MEFs were still more sensitive to apoptosis than were p53 $3^{-1-}$ MEFs (Fig. 1A), suggesting the involvement of other p53-dependent mechanisms.

The contribution of Noxa to the progression of the mitochondrial apoptotic pathway was examined in the above experimental setting by analyzing cytochrome $c$ release and caspase activation. As shown in Figure 1B, the level of cytochrome $c$ release to the cytosol was lower by about threefold in Noxa ${ }^{-/-}$MEFs than in wildtype MEFs. The cleavage of LEHD- $p \mathrm{Na}$ and DEVD- $p \mathrm{Na}$, which are the substrates for caspase 9 and caspases 3 and 7, respectively, was also suppressed in $\mathrm{Noxa}^{-/-} \mathrm{MEFs}$ (Fig. 1C).

The apoptosis of thymocytes exposed to genotoxic stimuli, such as ionizing radiation, is p53-dependent (Clarke et al. 1993; Lowe et al. 1993b) but not Bax-dependent (Knudson et al. 1995). When we examined thymocytes from $\mathrm{Noxa}^{-/-}$and $\mathrm{Noxa}^{-/-} / \mathrm{Bax}^{-/-}$mice, they all underwent apoptosis as efficiently as did wild-type thymocytes (Fig. 1D), despite the induction of both Noxa and Bax mRNAs upon X-ray irradiation of the wild-type thymocytes (Supplementary Fig. 2A). These results support the notion that the mechanisms of p53-dependent apoptosis in response to DNA damage, in which genes hypostatic to $p 53$ are involved, vary depending on cell type and cell state.

\section{Functional interrelation between Noxa and Bax}

The BH3-only proteins of the Bcl-2 family generally exert their apoptotic function by interacting with other pro-apoptotic or prosurvival members (Bouillet and Strasser 2002). In this process, induction of pro-apoptotic Bax/Bak oligomerization and inhibition of the prosurvival members are both critical for the release of cytochrome $c$ from mitochondria (Bouillet and Strasser 2002). It is as yet unknown how Noxa contributes to this general scheme of apoptosis. In this regard, Noxa mRNA was induced by adriamycin treatment of the E1A-expressing wild-type MEFs (Supplementary Fig. 2B). However, the induction of Bax mRNA was not observed (Supplementary Fig. 2B), raising the possibility that the p53-dependent function of Bax is mediated at least in part by the p53-induced Noxa. We examined whether Noxa interacts with Bax by coimmunoprecipitation and coimmunostaining assays, but no evidence was obtained for such interaction (data not shown). In view of the previous results showing the interaction of Noxa with the prosurvival Bcl-2 or Bcl- $\mathrm{X}_{\mathrm{L}}$ (Oda et al. 2000), it is more likely that Noxa indirectly promotes Bax/Bak activation by inhibiting this class of prosurvival members.

Accordingly, we analyzed the activation of Bax molecules. First, the membrane insertion of Bax was evaluated based on its resistance to alkali extraction (Goping et al. 1998). In wild-type MEFs expressing E1A, the level of Bax molecules that acquired alkali resistance significantly increased after adriamycin treatment, but this increase was marginal in $\mathrm{Noxa}^{-1-}$ MEFs (Fig. 2A). Next, Bax oligomerization was analyzed by treating mitochondria from MEFs with the chemical cross-linker 1,6-bismaleimidohexane (BMH; Antonsson et al. 2001). As shown in Figure 2B, the formation of Bax oligomers was notably suppressed in Noxa ${ }^{-/-}$MEFs. Thus, the absence of Noxa affects the levels of Bax insertion and oligomer- 



Figure 2. Contribution of Noxa to activation of Bax and Bak. (A) Bax membrane insertion during E1A-dependent apoptosis. Control and E1A-expressing MEFs were treated with DMSO control buffer or adriamycin $(0.25 \mu \mathrm{g} / \mathrm{mL})$ for $6 \mathrm{~h}$. A protein sample $(10 \mu \mathrm{g})$ was separated into alkali-sensitive supernatant $(\mathrm{S})$ and alkali-resistant pellet $(\mathrm{P})$, and was loaded into the corresponding lane. Without stimulation, Bax molecules reside in the cytoplasm or are weakly attached to the surface of mitochondria, which are readily detached by alkali treatment. Thus, they are separated into the $S$ fraction upon alkali extraction. When inserted into the mitochondrial membrane, Bax molecules acquire alkali resistance and are separated into the $\mathrm{P}$ fraction (Goping et al. 1998). The level of Bax molecules that acquired alkali resistance is lower in E1A-expressing Noxa $^{-/-}$MEFs after adriamycin treatment than in similarly treated wild-type (WT) MEFs. IB indicates immunoblot. $(B)$ Bax oligomerization during E1A-dependent apoptosis. Control and E1A-expressing MEFs were treated with DMSO control buffer or adriamycin $(0.25 \mu \mathrm{g} / \mathrm{mL})$ for $6 \mathrm{~h}$, and subsequently, Bax oligomerization was analyzed through BMH cross-linking. A cross-linked protein sample (40 $\mu \mathrm{g})$ was loaded into each lane. Markers M, D, and Tr correspond to the sizes of the monomer, dimer, and trimer, respectively. $(C)$ Bak oligomerization during E1A-dependent apoptosis analyzed as in B. Markers $M$ and D correspond to the sizes of the monomer and dimer, respectively. (ast; ) An intramolecularly oligomerized Bak monomer. $(D)$ Colony formation of MEFs expressing E1A and Ras on medium containing methylcellulose. Wild-type (WT) and Noxa ${ }^{-/-}$MEFs (left) as well as Noxa ${ }^{-/-}$and Noxa ${ }^{-1-} / \mathrm{Bax}^{-/-}$MEFs (right), were each prepared from the same litter. Values

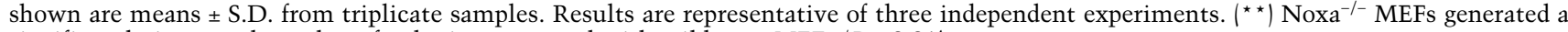
significantly increased number of colonies compared with wild-type MEFs $(P<0.01)$.

ization in the p53-dependent apoptosis. In addition, Bak dimerization was also suppressed by the absence of Noxa (Fig. 2C). It is likely that Noxa exerts its function by promoting the functions of Bax and Bak, indirectly by inhibiting the functions of prosurvival members of the Bcl-2 family (Oda et al. 2000).

It is worth noting that Noxa mRNA is induced in nonE1A-expressing MEFs treated with adriamycin at a level similar to that of the MEFs expressing E1A (Supplementary Fig. 2B,C), but the apoptotic event is selectively induced in the latter cells (Fig. 1A). This observation suggests that Noxa expression per se is insufficient to evoke apoptotic response, and it requires the expression of the E1A oncoprotein. In view of the fact that a low-level membrane insertion of Bax occurs after E1A expression without adriamycin treatment (Fig. 2A), E1A may sensitize the cells to the Noxa-dependent apoptosis.

\section{Oncogene-induced cell transformation in the absence of Noxa}

The role of p53-mediated apoptosis in suppressing cell transformation is well documented (Lowe et al. 1994), and the involvement of Bax in this p53-dependent suppression of transformation has also been reported (McCurrach et al. 1997). To examine the contribution of Noxa, we expressed E1A and Ras in MEFs of different genotypes (wild-type, $\mathrm{Noxa}^{-/-}, \mathrm{Bax}^{-/-}, \mathrm{p} 53^{-/-}$, and Noxa ${ }^{-/}$ $-/ \mathrm{Bax}^{-1} \mid$ and analyzed the formation of colonies on a medium containing methylcellulose. As shown in Figure 2D, Noxa ${ }^{-/-}$MEFs showed an increase in the number of colonies ( 2.5-fold) compared with that of wild-type MEFs. Furthermore, Noxa ${ }^{-/-} / \mathrm{Bax}^{-/-} \mathrm{MEF}$ showed more than twofold increase in the number of colonies compared with either of the single mutant MEFs (Fig. 2D). These results suggest that Noxa may represent a tumor susceptibility gene, and further support the notion that Noxa and Bax have overlapping and distinct functions from one another.

\section{Role of Noxa in the apoptotic response to severe DNA damage}

When cells are subjected to severe DNA damage, for example, by prolonged exposure to DNA-damaging agents, they eventually undergo apoptosis even in the absence of oncogene expression (Sen and D'Incalci 1992).p53 is also involved in this apoptotic response; however, p53 may activate a survival pathwayls) (Hawkins et al. 1996; Deverman et al. 2002). In this regard, p21 WAF1/Cip1 (hereafter referred to as $p 21)$, a cyclin-dependent kinase inhibitor, induces $\mathrm{Rb}$ dephosporylation, and this $\mathrm{Rb}$ activation pathway might protect cells from apoptosis (Deverman et al. 2002; Gartel and Tyner 2002). In effect, p53 critically determines the fate of cells by balancing the two opposite pathways of cellular responses. Interestingly, Noxa mRNA was up-regulated upon treatment with etoposide and ultraviolet (UV), which was substantially impaired in $\mathrm{p}^{-/-}$MEFs (Fig. 3A), suggesting the potential role of Noxa in the apoptotic limb of p53 responses.

To gain insight into the balancing mechanism mediated by $\mathrm{p} 53$, we examined the DNA damage-induced apoptosis of wild-type, $\mathrm{p} 53^{-/-}, \mathrm{Noxa}^{-/-}$, and $\mathrm{p} 21^{-/-}$MEFs. The induction of apoptosis by etoposide, adriamycin, or cisplatin treatment for a prolonged period occurred more effectively in $\mathrm{p} 53^{-/-}$and $\mathrm{p} 21^{-/-}$MEFs than in wild-type 
Shibue et al.
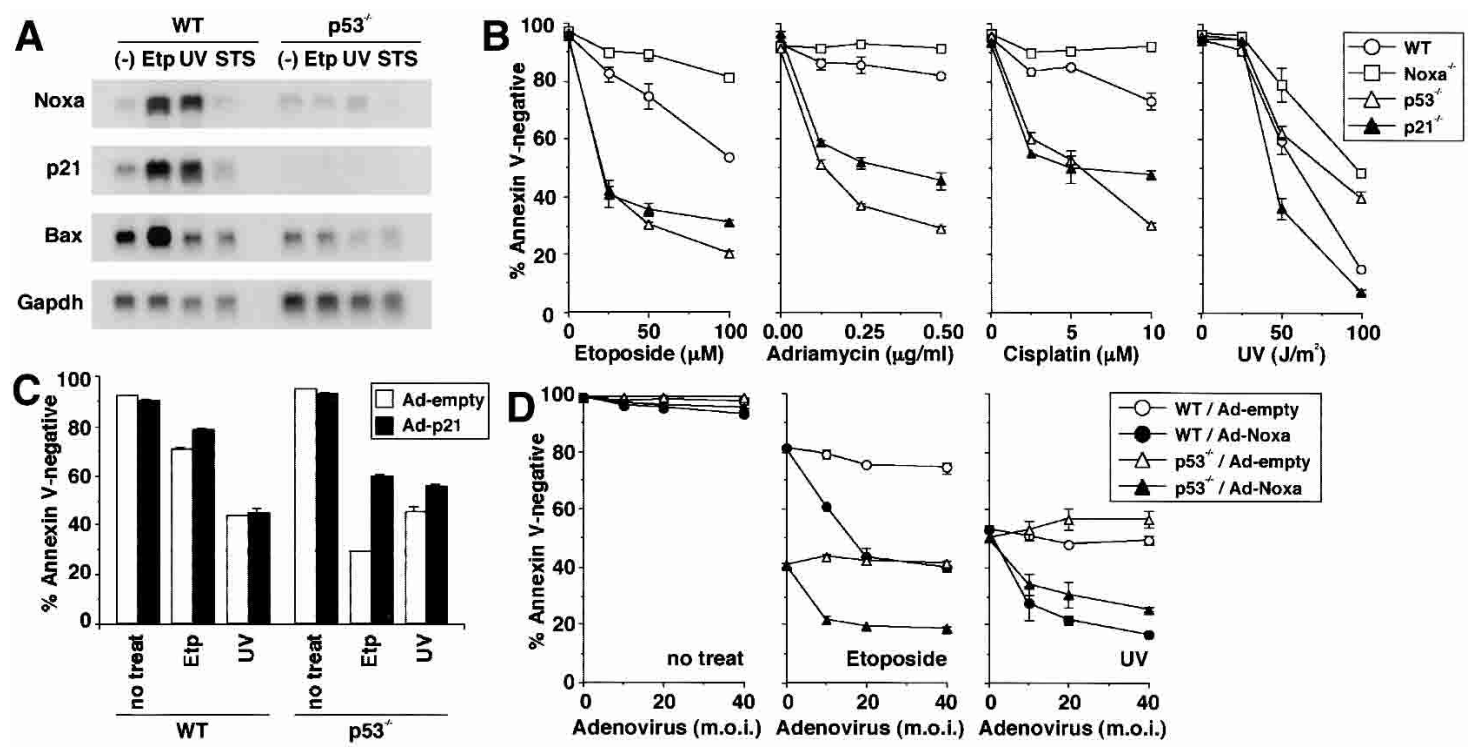

Figure 3. p21-mediated survival pathway and Noxa-mediated apoptotic pathway in MEFs with severe DNA damage. $(B-D)$ Values shown are mean \pm S.D. from triplicate samples, and results are representative of three independent experiments. $(A)$ Noxa, p21, and Bax mRNA expressions after treatment with apoptogenic agents. MEFs were treated with etoposide $(60 \mu \mathrm{M}$ for $6 \mathrm{~h}), \mathrm{UV}\left(60 \mathrm{~J} / \mathrm{m}^{2}, 6 \mathrm{~h}\right.$ prior to RNA preparation), or staurosporin (300 nM for $6 \mathrm{~h}$ ) or were left untreated. (Etp) Etoposide; (STS) staurosporin. (B) Apoptosis of MEFs induced by DNA-damaging agents. MEFs were treated with etoposide (for $36 \mathrm{~h}$ ), adriamycin (for $72 \mathrm{~h}$ ), cisplatin (for $72 \mathrm{~h}$ ), or UV (36 h prior to the cell viability assay). Wild-type (WT) and Noxa ${ }^{-/-}$MEFs were prepared from the same litter. Contrary to the data shown here, apoptosis caused by staurosporin or an anti-Fas antibody normally occurred in Noxa ${ }^{-/-}$MEFs (data not shown). (C) Effect of ectopic expression of p21 on etoposide- and UV-induced apoptosis. MEFs were infected with control (Ad-empty) or p21-expressing adenovirus (Ad-p21) at multiplicity of infection (m.o.i.) of 100. Twelve hours after infection, MEFs were treated with etoposide $(50 \mu \mathrm{M}$, for $36 \mathrm{~h})$ or UV $\left(50 \mathrm{~J} / \mathrm{m}^{2}, 36 \mathrm{~h}\right.$ prior to the cell viability assay) or were left untreated. $(D)$ Effect of ectopic expression of Noxa in the presence or absence of DNA-damaging agents. MEFs were infected with control (Ad-empty) or Noxa-expressing adenovirus (Ad-Noxa). Twelve hours after infection, MEFs were treated with etoposide (50 $\mu \mathrm{M}$, for $36 \mathrm{~h}$ ) or UV $\left(50 \mathrm{~J} / \mathrm{m}^{2}, 36 \mathrm{~h}\right.$ prior to the cell viability assay) or were left untreated.

MEFs (Fig. 3B). Notably, Noxa ${ }^{-/-}$MEFs appeared to be more resistant to apoptosis than were wild-type MEFs (Fig. 3B), an observation opposite to that of the $\mathrm{p} 53^{-/-}$ MEFs. These results suggest that the p53-dependent survival pathway via activation of the $p 21$ gene is dominant over the p53-dependent apoptotic pathway, in which Noxa is also involved, at least in this experimental setting.

Interestingly, p21-/- MEFs were highly sensitive to UV-induced apoptosis, but $\mathrm{p} 53^{-/-}$MEFs were not, rather they were more resistant than were wild-type MEFs (Fig. 3B). These observations can be interpreted as follows. Unlike the cases of other genotoxic stimuli, the p53dependent apoptotic pathway becomes dominant over the p21-mediated survival pathway by UV irradiation. As a result, the loss of the survival pathway caused by the p53 deficiency was fully counterbalanced by the loss of the otherwise dominant apoptotic pathway. It is worth noting that $\mathrm{Noxa}^{-/-}$MEFs were again found to be the most resistant among the four types of MEFs (Fig. 3B).

Based on these findings, at least three regulatory pathways may be involved in the apoptotic response in MEFs with severe DNA damage. As is evident from the apoptosis observed in $\mathrm{p}^{-1-}$ MEFs, a pathway(s) that triggers apoptosis independent of p53 is involved. In addition, p53 activation results in the activation of the two opposite pathways, that is, the survival and apoptotic pathways, in which p21 and Noxa are involved, respectively. In agreement with the role of p21 in the survival pathway, the death of $\mathrm{p} 53^{-1-}$ MEFs caused by etoposide or UV treatment was partially rescued by an ectopic expression of p21 (Fig. 3C). Furthermore, the expression of the papillomavirus-encoded oncoprotein E7, which disrupts the $\mathrm{Rb}$ family-mediated cell cycle regulation, enhances apoptosis upon treatment with etoposide or UV (Supplementary Fig. 3A), an observation consistent with the report that the $\mathrm{p} 21$ functions upstream of $\mathrm{Rb}$ in the induction of the cell survival mechanism (Gartel and Tyner 2002).

Similar to the oncogene-dependent function of Noxa described above, the function of Noxa in this apoptotic response is dependent on cellular conditions. In fact, when wild-type MEFs were infected with the Noxaexpressing adenovirus, apoptosis was not observed, but this expression notably enhanced the apoptotic response to etoposide or UV (Fig. 3D). These responses were also observed in p53 ${ }^{-/}$MEFs (Fig. 3D), suggesting that Noxa cooperates with the p53-independent apoptotic pathway, which enhances the gross apoptotic response.

We also asked whether the p53-dependent induction of Noxa is critical to its function in apoptosis. For this purpose, we expressed the papillomavirus-encoded oncoprotein E6, which facilitates p53 degradation, in wild-type and $\mathrm{Noxa}^{-/-}$MEFs. In this experimental setting, the Noxa mRNA induction in wild-type MEFs was clearly suppressed by E6 (Supplementary Fig. 3B). It was then found that E6-expressing wild-type MEFs are more resistant to UV-induced apoptosis than are control wild-type MEFs (Supplementary Fig. 3C). In contrast, the expression of E6 did not result in increased resistance of $\mathrm{Noxa}^{-/-}$MEFs (Supplementary Fig. 3C). These results in toto support the notion that the p53-dependent induc- 
tion of the Noxa gene is critical for the UV-induced apoptosis.

\section{Increased resistance of Noxa-deficient mice to DNA-damage-induced death}

The above results prompted us to examine the in vivo role of Noxa by whole-body irradiation (10 Gy) of mice, which induces apoptosis in both epithelial cells in the stem cell region of small intestinal crypts (hereafter termed ESS) and cells in lamina propria (termed CLP; Merritt et al. 1994; Paris et al. 2001). The apoptosis of ESSs is completely suppressed, whereas that of the CLPs still occurs in p53 ${ }^{-/-}$mice (Merritt et al. 1994; Paris et al. 2001), suggesting that the p53-dependent survival pathway dominates in the CLPs.

A
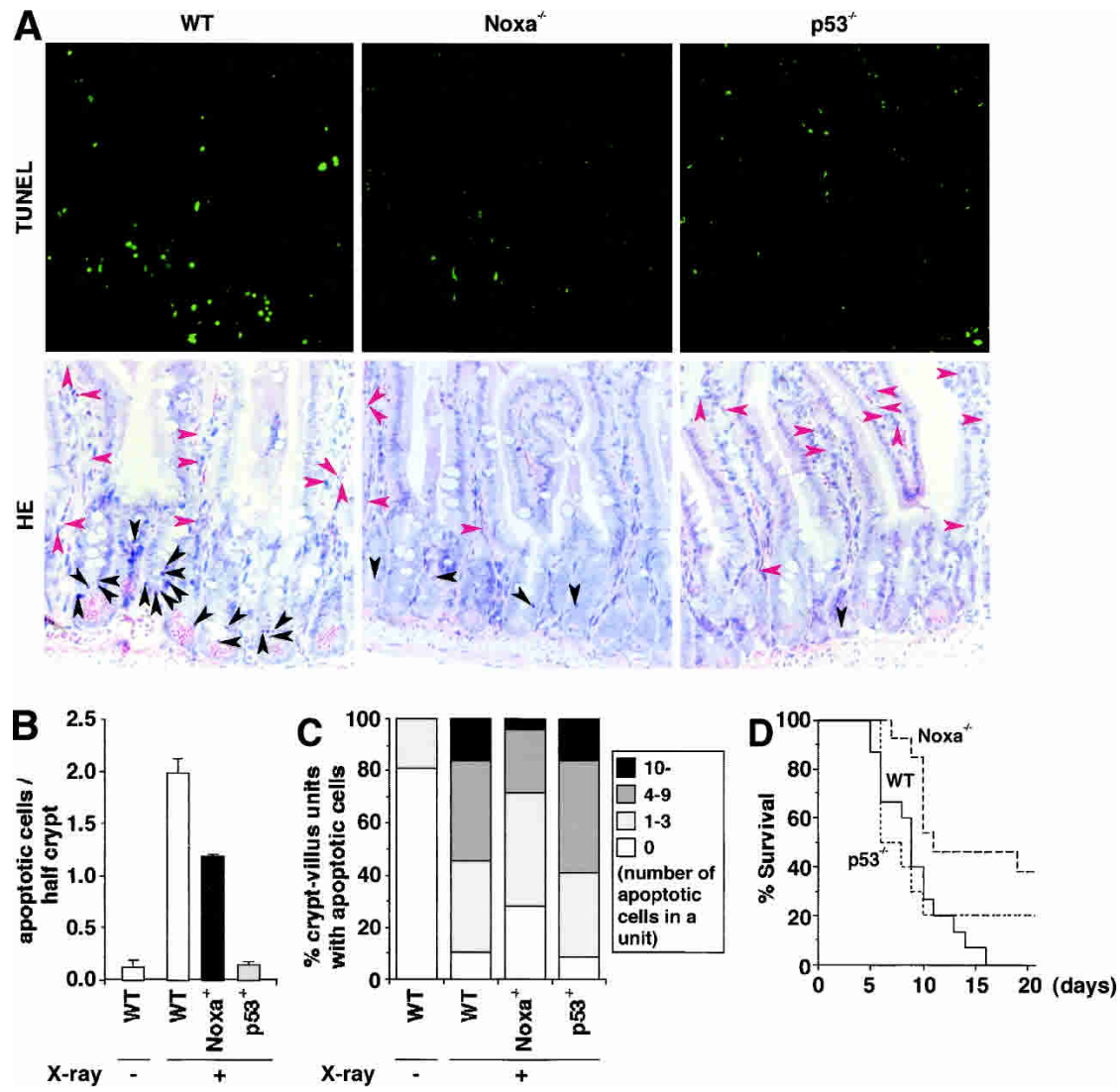

Figure 4. Resistance to DNA damage-induced apoptosis in vivo in the absence of Noxa. $(A)$ Radiation-induced apoptosis of cells in small intestine. Sections of the jejunum from X-rayirradiated $(10 \mathrm{~Gy})$ mice were analyzed. In the TUNEL assay $(t o p)$, TUNEL-positive cells are identified by the green fluorescence. In HE staining (bottom), apoptotic cells in the lower third (cell position 1-7, encompassing the stem cell region) of crypts are indicated by black arrowheads, and those in the lamina propria are indicated by red arrowheads. $(B)$ Histograms of apoptotic cells in the lower third of crypts. Approximately 150 half-crypts were scored per section. Values shown are mean \pm S.D. from three sections, each obtained from different mice. $(C)$ Frequency histograms of apoptotic cells in the lamina propria. Approximately 100 crypt-villus units were scored per section. Data shown are means from three sections each obtained from different mice. $(D)$ Survival curve of mice after whole-body irradiation. Seven groups of littermates including 15 wild-type (WT) mice and $13 \mathrm{Noxa}^{-/-}$mice together with 10 p53 $3^{-1-}$ mice were subjected to X-ray irradiation $(10 \mathrm{~Gy})$, and the survival of these mice for 20 $\mathrm{d}$ after irradiation are shown. The survival of mice was scored up to $30 \mathrm{~d}$ after irradiation. The survival periods (mean \pm S.D.) of wild-type (WT), Noxa ${ }^{-/-}$, and p53 ${ }^{-/-}$mice were $9.1 \pm 3.3 \mathrm{~d}$, $17.5 \pm 9.5 \mathrm{~d}$, and $10.7 \pm 7.9 \mathrm{~d}$, respectively. The survival periods of $\mathrm{Noxa}^{-/-}$mice was significantly longer than those of wild-type mice or $\mathrm{p} 53^{-/-}$mice $(P<0.01$ vs. wild-type, $P<0.05$ vs. $\left.\mathrm{p} 53^{-/-}\right)$.
As shown in Figure 4A and B, the apoptosis of ESSs that Noxa is involved in the DNA damage-induced, p53-


p53 $3^{-1-}$ mice. These results support the above notion that the data shown above, the life span of $\mathrm{Noxa}^{-/}$mice after type or p53 $3^{-/-}$mice (Fig. 4D).

The results presented in this report indicate the critiin vitro and in vivo. On the other hand, our study further suggests that the contribution of the target genes of p53 is dependent on cell type and cell state. Our results also suggest that Noxa is involved in the elimination of cancerous cells. Because Noxa expression per se does not cause apoptosis in normal fibroblasts, the ectopic expression of Noxa may provide a new strategy for selectively inducing apoptosis in cancerous cells.

\section{Materials and methods}

Gene targeting and generation of $\mathrm{Nox}^{-/-}$mice The Noxa genomic DNA was previously described (Oda et al. 2000). The targeting vector was designed to replace a $2.4-\mathrm{kb}$ fragment containing exons 1 and 2 of the Nox $a$ gene with a neomycinresistance gene (neo) derived from pMC1 neo poly A (Stratagene). A short arm and a long arm of the homology region from the CCE genome were amplified by PCR. A herpes simplex virus thymidine kinase gene (HSV-TK) was inserted into the $3^{\prime}$ end of the vector. The chimeric and mutant mice were generated as described previously (Takeda et al. 1996). The mutant mice were backcrossed with C57BL/6 mice at least five times before using in the experiments.

\section{Detection of apoptosis}

Apoptosis of MEFs was quantitated by staining with annexin V-FITC or annexin V-Cy3 (MBL) followed by flow cytometric analysis using a FACScalibur (Becton-Dickinson). Apoptosis of thymocytes and cells in the lamina propria of small intestine was quantitated by the TUNELreaction using the In Situ Cell Death Detection Kit, Flourescein (Roche Diagnostics) followed by flow cytometry and microscopy, respectively. Apoptosis of the epithelial cells in the lower third of small intestinal crypts was quantitated by detecting the nuclear morphological change through hematoxylin and eosin (HE) staining.

\section{Analysis of Bax/Bak activation}

For the detection of Bax insertion, MEFs were collected, washed with PBS, and resuspended in 0.1 $\mathrm{M} \mathrm{Na}_{2} \mathrm{CO}_{3}$ (pH 11.5). Subsequently, MEFs were homogenized with a polytron homogenizer for three bursts of $10 \mathrm{sec}$ each and were incubated for $30 \mathrm{~min}$ on ice. Then the membranes and organelles were pelleted by centrifugation $(100,000 \times g$ for $45 \mathrm{~min}$ at $4^{\circ} \mathrm{C}$ ).

For BMH cross-linking, MEFs were harvested 
in isotonic buffer $(210 \mathrm{mM}$ mannitol, $70 \mathrm{mM}$ sucrose, $1 \mathrm{mM}$ EGTA, 10 $\mathrm{mM}$ Hepes at $\mathrm{pH} 7.5)$ supplemented with protease inhibitors $(1 \mathrm{mM}$ PMSF, $400 \mu \mathrm{M} \mathrm{Na}_{3} \mathrm{VO}_{4}, 10 \mu \mathrm{g} / \mathrm{mL}$ aprotinin, and $10 \mu \mathrm{g} / \mathrm{mL}$ leupeptin). Then MEFs were homogenized by eight passages through a 25 -gauge needle, and the suspension was centrifuged at $600 \times g$ for $10 \mathrm{~min}$ at $4^{\circ} \mathrm{C}$. This procedure was repeated twice, and supernatants from each step were collected and centrifuged at $8000 \times g$ for $10 \mathrm{~min}$ at $4^{\circ} \mathrm{C}$. The pellet was washed and resuspended in isotonic buffer to a final concentration of 0.5 $\mathrm{mg} / \mathrm{mL}$ protein, and then $11 \mathrm{mM}$ BMH (Pierce) solution in DMSO was added at a 1:11 dilution. After incubating for $30 \mathrm{~min}$ at room temperature, cross-linking reaction was quenched by adding DTT to a final concentration of $25 \mathrm{mM}$, followed by centrifugation to pellet mitochondria, which was subsequently analyzed by immunoblotting.

\section{Whole-body irradiation}

Eight-week-old mice were X-ray irradiated (10 Gy). For the quantitation of apoptosis, mice were euthanized $6 \mathrm{~h}$ after irradiation, and subsequently, the jejunum was harvested and fixed in $4 \%$ formaldehyde overnight at room temperature. Sections were prepared after embedding the samples in paraffin.

Other methods are described in Supplemental Material.

\section{Acknowledgments}

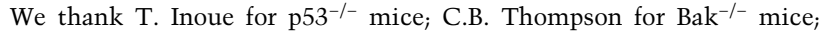
T. Nakajima for the E1A expression vector; T. Kiyono for the vectors of E6 and E7; Y. Taya, K. Honda, and H. Takayanagi for invaluable advice; and T. Yokochi and J. Nemoto for technical assistance. This work was supported in part by a grant for Advanced Research on Cancer from the Ministry of Education, Culture, Sports, Science and Technology of Japan and grants of the Virtual Research Institute of Aging of Nippon Boehringer Ingelheim. T.S. is a research fellow of the Japan Society for the Promotion of Science.

The publication costs of this article were defrayed in part by payment of page charges. This article must therefore be hereby marked "advertisement" in accordance with 18 USC section 1734 solely to indicate this fact.

\section{References}

Antonsson, B., Montessuit, S., Sanchez, B., and Martinou, J.C. 2001. Bax is present as a high molecular weight oligomer/complex in the mitochondrial membrane of apoptotic cells. J. Biol. Chem. 276: 1161511623.

Bouillet, P. and Strasser, A. 2002. BH3-only proteins: Evolutionarily conserved proapoptotic Bcl-2 family members essential for initiating programmed cell death. J. Cell Sci. 115: 1567-1574.

Clarke, A.R., Purdie, C.A., Harrison, D.J., Morris, R.G., Bird, C.C., Hooper, M.L., and Wyllie, A.H. 1993. Thymocyte apoptosis induced by p53-dependent and independent pathways. Nature 362: 849-852.

Deverman, B.E., Cook, B.L., Manson, S.R., Niederhoff, R.A., Langer, E.M., Rosova, I., Kulans, L.A., Fu, X., Weinberg, J.S., Heinecke, J.W., et al. 2002. Bcl-xL deamidation is a critical switch in the regulation of the response to DNA damage. Cell 111: 51-62.

Gartel, A.L. and Tyner, A.L. 2002. The role of the cyclin-dependent kinase inhibitor p21 in apoptosis. Mol. Cancer Ther. 1: 639-649.

Goping, I.S., Gross, A., Lavoie, J.N., Nguyen, M., Jemmerson, R., Roth, K., Korsmeyer, S.J., and Shore, G.C. 1998. Regulated targeting of BAX to mitochondria. J. Cell Biol. 143: 207-215.

Hawkins, D.S., Demers, G.W., and Galloway, D.A. 1996. Inactivation of p53 enhances sensitivity to multiple chemotherapeutic agents. Cancer Res. 56: 892-898.

Knudson, C.M., Tung, K.S., Tourtellotte, W.G., Brown, G.A., and Korsmeyer, S.J. 1995. Bax-deficient mice with lymphoid hyperplasia and male germ cell death. Science 270: 96-99.

Ko, L.J. and Prives, C. 1996. p53: Puzzle and paradigm. Genes \& Dev. 10: 1054-1072.

Lengauer, C., Kinzler, K.W., and Vogelstein, B. 1998. Genetic instabilities in human cancers. Nature 396: 643-649.

Lowe, S.W., Ruley, H.E., Jacks, T., and Housman, D.E. 1993a. p53-dependent apoptosis modulates the cytotoxicity of anticancer agents. Cell 74: 957-967.

Lowe, S.W., Schmitt, E.M., Smith, S.W., Osborne, B.A., and Jacks, T. 1993b. p53 is required for radiation-induced apoptosis in mouse thymocytes. Nature 362: 847-849.

Lowe, S.W., Jacks, T., Housman, D.E., and Ruley, H.E. 1994. Abrogation of oncogene-associated apoptosis allows transformation of p53-deficient cells. Proc. Nat1. Acad. Sci. 91: 2026-2030.

McCurrach, M.E., Connor, T.M., Knudson, C.M., Korsmeyer, S.J., and Lowe, S.W. 1997. Bax-deficiency promotes drug resistance and oncogenic transformation by attenuating p53-dependent apoptosis. Proc. Nat1. Acad. Sci. 94: 2345-2349.

Merritt, A.J., Potten, C.S., Kemp, C.J., Hickman, J.A., Balmain, A., Lane, D.P., and Hall, P.A. 1994. The role of p53 in spontaneous and radiation-induced apoptosis in the gastrointestinal tract of normal and p53-deficient mice. Cancer Res. 54: 614-617.

Nakano, K. and Vousden, K.H. 2001. PUMA, a novel proapoptotic gene, is induced by p53. Mol. Cell 7: 683-694.

Oda, E., Ohki, R., Murasawa, H., Nemoto, J., Shibue, T., Yamashita, T., Tokino, T., Taniguchi, T., and Tanaka, N. 2000. Noxa: A BH3-only member of the Bcl-2 family and candidate mediator of p53-induced apoptosis. Science 288: 1053-1058.

Paris, F., Fuks, Z., Kang, A., Capodieci, P., Juan, G., Ehleiter, D., Haimovitz-Friedman, A., Cordon-Cardo, C., and Kolesnick, R. 2001. Endothelial apoptosis as the primary lesion initiating intestinal radiation damage in mice. Science 293: 293-297.

Rich, T., Allen, R.L., and Wyllie, A.H. 2000. Defying death after DNA damage. Nature 407: 777-783.

Schmitt, C.A., Fridman, J.S., Yang, M., Baranov, E., Hoffman, R.M., and Lowe, S.W. 2002. Dissecting p53 tumor suppressor functions in vivo. Cancer Cell 1: 289-298.

Sen, S. and D'Incalci, M. 1992. Apoptosis: Biochemical events and relevance to cancer chemotherapy. FEBS Lett. 307: 122-127.

Takeda, K., Tanaka, T., Shi, W., Matsumoto, M., Minami, M., Kashiwamura, S., Nakanishi, K., Yoshida, N., Kishimoto, T., and Akira, S. 1996. Essential role of Stat6 in IL-4 signalling. Nature 380: 627-630.

Vousden, K.H. and Lu, X. 2002. Live or let die: The cell's response to p53. Nat. Rev. Cancer 2: 594-604.

Wei, M.C., Zong, W.X., Cheng, E.H., Lindsten, T., Panoutsakopoulou, V., Ross, A.J., Roth, K.A., MacGregor, G.R., Thompson, C.B., and Korsmeyer, S.J. 2001. Proapoptotic BAX and BAK: A requisite gateway to mitochondrial dysfunction and death. Science 292: 727-730.

Yu, J., Zhang, L., Hwang, P.M., Kinzler, K.W., and Vogelstein, B. 2001 PUMA induces the rapid apoptosis of colorectal cancer cells. Mol. Cell 7: 673-682.

Zhou, B.B. and Elledge, S.J. 2000. The DNA damage response: Putting checkpoints in perspective. Nature 408: 433-439. 


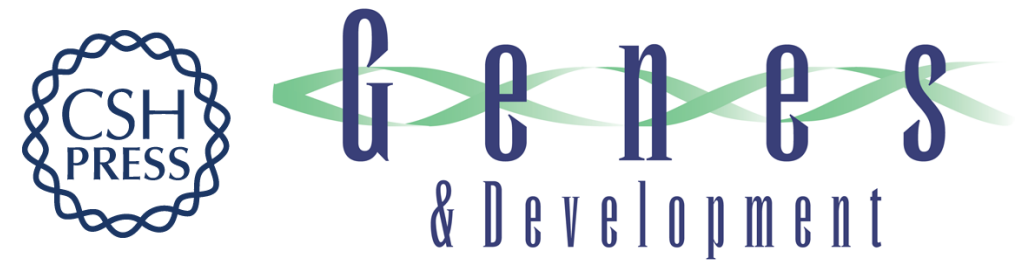

\section{Integral role of Noxa in p53-mediated apoptotic response}

Tsukasa Shibue, Kiyoshi Takeda, Eri Oda, et al.

Genes Dev. 2003, 17:

Access the most recent version at doi:10.1101/gad.1103603

Supplemental

Material

References

\section{License}

Email Alerting Service
This article cites 26 articles, 13 of which can be accessed free at: http://genesdev.cshlp.org/content/17/18/2233.full.html\#ref-list-1

http://genesdev.cshlp.org/content/suppl/2003/09/02/1103603.DC1

Receive free email alerts when new articles cite this article - sign up in the box at the top right corner of the article or click here.

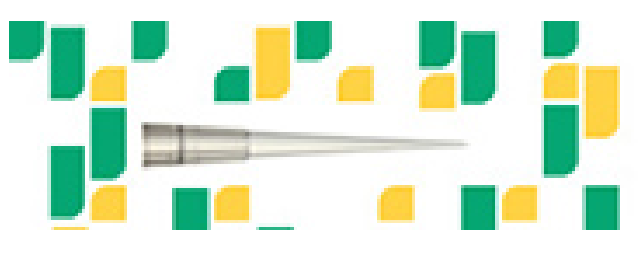

Focused on your science. 